\title{
Shared Value in Practice: TOMS Business Model
}

\author{
Katarzyna Bachnik, Justyna Szumniak-Samolej \\ Warsaw School of Economics, Warsaw, Poland
}

\begin{abstract}
The article deals with the idea of building a company around the corporate social responsibility (CSR) principles and designing a business model that is simultaneously economically viable, lucrative, and of social benefits. TOMS is analyzed as an example of a company that took this approach and succeeded. The main research questions try to examine the basic assumptions of TOMS business model in light of shared value concept and uncover the reasons of company's success. The authors claim that two factors played there a crucial role. Firstly the leader whose passion was so contagious that he/she managed to build the team and set up a company based on his/her ideas. Secondly TOMS business model concept (One for One) is convincing for customers who eagerly join the movement. This business case illustrates how a company that is based on social values can grow.

Keywords: corporate social responsibility (CSR), business model, TOMS, shared value, leadership
\end{abstract}

\section{Introduction}

Many enterprises make an effort to present themselves as social citizens and to prove their responsibility for their actions. It is especially true for medium and large companies. Their motives may differ a lot: from a desire to strengthen their image and support public relations programs with social component to a genuine engagement in solving serious global problems and in addressing serious social issues that develop in the socio-economic context. We can wonder if the chances of executing corporate social responsibility (CSR) concept in business environment are equal for all kinds of enterprises or if some of them have an easier path. Taking into account the extremes, we can benchmark market leaders and start-ups, companies with a solid market position and deep knowledge of the competition, customers, logistics, distribution, marketing and operations challenges and the emerging companies that have built their business model on CSR premises and will verify it.

TOMS is an example of a company that chose the second approach, and is authentic in what it is doing and succeeds. The key to its success is novel and convincing business model idea, effective leadership, and open communication with different groups of stakeholders.

The basic aim of this paper is to examine assumptions of TOMS business model in the context of CSR and shared values concept.

\section{What Is Business Model?}

Both academics and practitioners agree that a good business model idea can be a source of competitive

Katarzyna Bachnik, Ph.D., Assistant Professor, Department of Corporate Management, Warsaw School of Economics. Justyna Szumniak-Samolej, Ph.D., Assistant Professor, Department of Management Theory, Warsaw School of Economics.

Correspondence concerning this article should be addressed to Katarzyna Bachnik, Wawozowa 11/33, 02-796 Warsaw, Poland. E-mail: katarzynabachnik@gmail.com. 
advantage (Casadesus-Masanell \& Ricart, 2007; Magretta, 2002; Zott, Amit, \& Massa, 2010). However, while the expression "business model" has been widely used for a long time, there is no commonly accepted definition of what it really means. Business model is defined in many different perspectives and in many often contradictory ways. In the most general terms, a business model describes how the company generates profits (Płoszajski, 2011) or the way company operates (Casadesus-Masanell \& Ricart, 2007, p. 4). However, more and more business model definitions apart from earning profits emphasize the importance of value creation for customers and more broadly for stakeholders. For example, according to Osterwalder and Pigneur (2009), "A business model describes the rationale of how an organization creates, delivers, and captures value" (p. 14). What is important in creating and capturing value does not take place in a vacuum, but in the so-called value nets - an extensive networks of relationships between the company, its suppliers, partners, customers, and other external stakeholders (Normann \& Rammirez, 1993; Parolini, 1999).

Apart from the sole definitions, researchers agree on the meaning of building effective business model. There must be functions of business model considered in the first place here. Therefore companies must remember that business model serves few goals. It is built in order to (Chesbrough, 2007, p. 13):

(1) Articulate the value proposition for users;

(2) Identify a market segment (or segments);

(3) Define the structure of the value chain required by the company to create and distribute the offering and determine the complementary assets needed to support the company's position in this chain;

(4) Specify the revenue generation mechanism(s) and the cost structure;

(5) Describe the position of the company within the value network;

(6) Formulate the competitive strategy by which the innovating company will gain and hold advantage over rivals.

Business models can play a key role in explaining the competitive advantage and business performance. According to Chesbrough (2007), "A better business model often will beat a better idea or technology" (p. 12). But what is one of the main forces driving strategic renewal efforts of business around the world is the business model innovation (Casadesus-Masanell \& Ricart, 2007, p. 3). Markides (2008) argued that innovations in this area lead to fundamental changes in the market rules of competing. Business model innovations seem to be even more crucial than breakthrough products and service development because they are not so vulnerable to replication. It is much more difficult to imitate or copy them. They also allow new players to compete effectively against existing leaders who have much greater resources and experience.

\section{Business Model and Social Involvement of TOMS}

TOMS represents an example of such a novel and competitive business model. However, we need to highlight that beyond the economic rationale, it employs also the CSR idea. Actually, the strong and innovative social mission is the basis of this business model and the key reason of its success. From the beginning, apart from generating profits, the TOMS business model was intended to have a profound and positive impact on the society. It means that for-profit approach is accompanied by initiatives undertaken to address some global social problems. That is why it represents not only "business" model, but also "beyond-profit" model with a strong social mission. Its design proves the concept of a triple bottom line business model (Osterwalder \& Pigneur, 2009, p. 265) which focuses on seeking to minimize negative social and environmental impacts and maximize the positive impacts. 
The idea of setting up this company, stems from the recognition of a basic need - the need to protect feet in poor countries where scarce percentage of population can afford to buy shoes. The observation made by its founder Blake Mycoskie while traveling around Argentina, reminds in a way the movement started by Muhammad Yunus. Yunus transformed the lack of financing sources at the bottom of the pyramid into a business opportunity. By establishing a micro finance bank he supported the entrepreneurship of the poor, created them chances to live a better life and simultaneously stimulated the growth of his institution. This economic and social parallel can be also seen in the case of TOMS. Driven by the "One for One" (One person buys. One person is helped) concept, Blake Mycoskie established a company that is intended to "match every pair of shoes purchased with a pair of new shoes given to a child in need" (TOMS Our Movement, 2012). It means that for each pair of shoes sold, the company donates another one to people who need it. Mycoskie believed in this notion so much that engaged himself in its execution. His passion and devotion attracted employees, business partners, giving organizations and clients. Together they develop the company and collaborate for the common greater good.

The business model of the company is built upon the CSR principles. Apart from the idea to improve children's health and access to education in the long-term, the company tries to inhibit certain set of values and norms in all its operations: from relationships with employees, business partners, and vendors to contact with customers and third party organizations that deal with the beneficiaries directly.

The type of conducted business has been carefully considered in multi dimensions. These are not only shoes as a feet protection TOMS offers much more. They help fight social exclusion, give access to education and have better chances to contribute to the community's wellbeing and their own in the long run. As the company explains the reasons to choose shoes:

(1) Growing up barefoot: In many developing countries, children must walk barefoot for miles to school, without having access to clean water and medical help;

(2) Injury and disease: Hundreds of millions of children are at risk of injury, infection, and soil-transmitted diseases that most do not have access to prevent or treat;

(3) Education and opportunity: Children who are healthy are more likely to be successful students, and access to education is a critical determinant of long-term success;

(4) A better tomorrow: Healthy, educated children have a better chance of improving the future of their entire community (TOMS Why Shoes, 2012).

The shoe industry is the core line of TOMS's business, but the company expands and looks for new fields of social engagement. It has also paid attention to the eyewear problem recognizing that sight is also a fundamental human need and that "being able to give sight has a dramatic impact on a person's life" (TOMS About TOMS, 2012). It started to address this problem the same way it deals with the shoe delivery to those in need. For one sold pair of glasses, it provides adequate medical help to one person. This help may take the form of medical treatment, prescription glasses, or sight-saving surgery. Fulfilling its mission, the company celebrates and promotes every year in October - the World Sight Day in order to build awareness for the global issue of avoidable blindness and visual impairment.

\section{TOMS and the Shared Value Concept}

The business model of TOMS is closely linked to the idea of taking CSR initiatives into the strategic level. In other words, CSR projects are not moved to the periphery of company's activities, but they constitute the 
core. TOMS proved that aligning with CSR ideals can be fundamental for conducting successful business and that there is no need to give up on profits while striving for social goals and addressing social problems.

This approach corresponds with the notion that business and society can coexist on a win-win basis. The term "shared value", promoted lately by Porter and Kramer (2011) was coined to show the interdependencies between these two players. Porter and Kramer (2011) defined it as "policies and operating practices that enhance the competitiveness of a company while simultaneously advancing the economic and social conditions in the communities in which it operates" (p. 66). They claimed that the competitiveness of a company and the health of the communities around it are closely intertwined. Just as business operates within a broader environment and external communities, also the society cannot thrive without efficient, jobs-creating, and wealth generating enterprises. Therefore, instead of sticking to the profound belief that economic efficiency and social progress are mutually exclusive, it would be better to admit that businesses must reconnect company success with social progress. This approach involves creating economic value in a way that also creates value for society by addressing its needs and challenges. As a consequence, companies may look there for sources of competitive advantage. In the first place it means identifying those societal needs, benefits, and harms that company can address with its products and services. It may be enough to link existing products with those needs or they may be embodied in a new set of offerings. This is closely interrelated with the growth stage of the company, its resource base and growth plans. But there are many ways in which exploration of societal challenges may increase productivity of a company (see Figure 1). Corporate investing in a wellness program brings benefits to the society as employees become healthier and happier, but the company itself also can benefit from greater productivity and lower costs due to employee absences and medical treatment. The same story goes for TOMS, shoes, and eyeglasses.

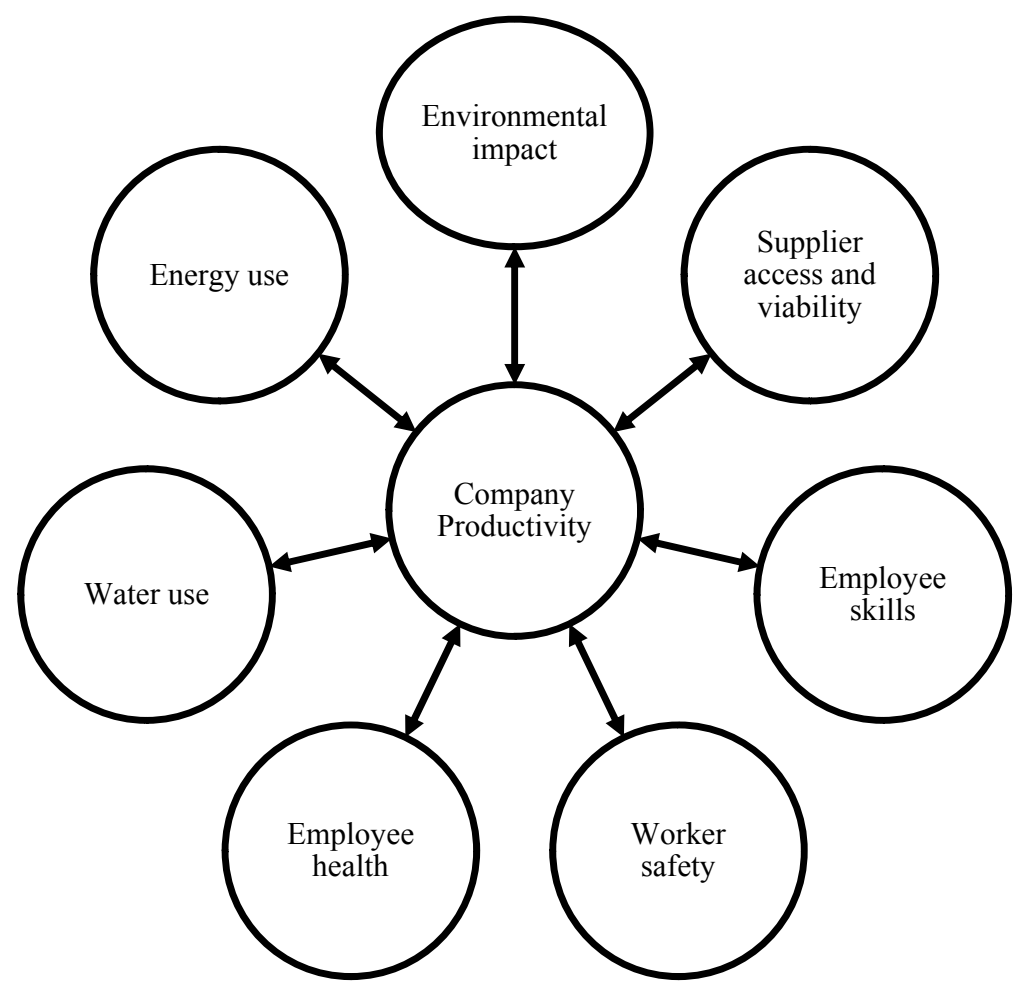

Figure 1. Organizational productivity and societal challenges. Source: Porter and Kramer (2011, p. 68). 
Opportunities for generating shared value exist as solving societal problems may contribute to minimizing economic costs in the business value chain. Excess packaging of products and greenhouse gases not only harm environment, but also deteriorate the quality of human's life and generate extra costs for companies. In this context the word "synergy" is appropriate, as society will advance more rapidly and business will grow in a constant and sustainable way. Joining forces to mitigating these negative effects seems reasonable, though counterintuitive. As Porter and Kramer (2011) point out:

Shared value offers corporations the opportunity to utilize their skills, resources, and management capability to lead social progress in ways that even the best-intentioned governmental and social sector organizations can rarely match. In the process, businesses can earn the respect of society again. (p. 77)

However, undertaking efforts to create shared value has much greater potential than that. It also stimulates innovation. Once new needs of stakeholders are identified, companies will seek ways to meet them. Once environmental issues are openly discussed, companies will seek new ways to address them. Pure compliance with appropriate regulations is not enough, nor is philanthropy or sustainability. That is why another aspect of dealing with this complexity of CSR initiatives is collaboration between for-profit and citizen-sector organizations. This framework is called hybrid value chain by Drayton and Budinich (2010), but the core is coherent with the shared value concept. Hybrid value chains also capitalize on the complementary strengths of engaged parties in order to create real economic and social value. They stress the need for partnership. On the one hand there are businesses that offer scale, expertise in manufacturing, operations, and financing. On the other hand, there are social organizations that bring lower costs, strong social networks, and deep insights into customers and communities. Encouraging both sides to cooperate may result in profits, innovations, efficiency rise, diminishing externalities of business activities and dealing with the scope and scale of global societal concerns. In order to make this partnership work, four criteria has to be met (Drayton \& Budinich, 2010, p. 64):

(1) The business has the potential to be large in scale and to cross borders;

(2) For-profits and social entrepreneurs work together to create multiple kinds of value;

(3) Consumers - broadly defined - pay for the product or service;

(4) A system - changing idea provides the basis for new competition.

The history of TOMS proves that it is possible to form such partnerships and achieve set goals - in economic and social terms. TOMS does not provide gifts alone. The company works to establish shoe-giving partnerships with humanitarian organizations worldwide that have deep experience and a long-term presence in the countries and communities they serve. They engage in joint effort and collaborate in order to (TOMS How We Give, 2012):

(1) Identify communities that need shoes ("Together, we find communities that will benefit most from TOMS shoes due to economic, health, and educational needs, and where local businesses will not be negatively affected");

(2) Give shoes that fit ("Our giving partners order the sizes children in their community need. We make the shoes to order to ensure children are given new shoes that fit them");

(3) Improve the impact of the shoes ("Children who are given TOMS shoes receive them as part of larger health and education programs run by our giving partners. These programs help children get the care and opportunity they need to keep them healthy and in school"); 
(4) Give children shoes as they grow ("Children grow fast! TOMS works to give shoes to children in need throughout their childhood. Once we identify a community that needs shoes, we continue to give to the children in that community to help them stay healthy and in school");

(5) Receive feedback and improve ("We rely on our incredible giving partners to provide feedback on shoes' fit and durability, the giving process and the needs of the community allowing us to continually improve").

TOMS assumes that acting within partnerships instead of engaging itself in charitable activities alone (in isolation) can produce better results. With the help of humanitarian organizations it finds communities that will benefit most from shoes due to economic, health, and educational needs. Children who get TOMS shoes receive them as a part of a larger health and educational programs run by giving partners. These programs help children get the care and opportunity they need to keep them healthy and educated (TOMS One for One Giving Report, 2012).

The company also pays attention to cultural differences that may undermine its social efforts. For example, it tries to understand local norms of behaviors so that its donations are accepted with gratitude and not rejected (which may happen in communities where shoes are a rare phenomenon). The most common shoe given is black since black shoes are required for school in many countries. However, the shoes TOMS offers are adjusted to local needs and often designed as ordered - it means that the style and fit are evolving all the time. The company is also working on developing additional shoe types based on the feedback from giving partners (TOMS One for One Giving Report, 2012). TOMS also pays great attention to justice. It tries to prevent a situation when granting free shoes might be perceived as unfair.

It must be underlined that TOMS is not only a commercial company. It contributed a lot to create a potent social movement around their idea. Every year in April TOMS organizes "One Day Without Shoes". It is a set of events taking place worldwide aimed at gaining people walking this day barefoot in order to raise awareness about the impact shoes can have in a child's life. In 2012 people went without shoes at over 3,000 events in 50 countries and on 275 campuses around the globe (TOMS One Day Without Shoes, 2012).

\section{Conclusions}

TOMS has succeeded precisely because a new business model has been created. Blake Mycoskie who has never made a pair of shoes, attended fashion school, and had no experience in retail, having less than 5,000 dollars and basing on the simple idea created one of the fastest-growing shoe companies in the world (TOMS Founder Blake Mycoskie: Start Something That Matters, 2012). Four years after its foundation (in September 2010) TOMS has given over a million pairs of new shoes to children in the need around the world (TOMS One for One, 2012). Currently their factories are located in three countries and they give their shoes in 23 countries (TOMS One for One Giving Report, 2012). Their eyeglasses business is also expanding. This means that the company succeeded in focusing customers' attention towards two serious global problems and won them in order to solve them. Hopefully, the scope of its functioning will broaden step by step contributing to some extent to providing better quality of life and a higher probability for a better future to those that are faced with tough living conditions and unable to take care of themselves.

This business case shows how businesses can grow by helping others and by sticking to the corporate social responsibility concept. It also sheds light on a modern leadership style. 


\section{References}

Casadesus-Masanell, R., \& Ricart, J. E. (2007). Competing through business models. Working Paper WP-713, IESE Business School, University of Navarra, Navarra.

Chesbrough, H. (2007). Business model innovation: It is not just about technology anymore. Strategy and Leadership, 35(6), 12-17.

Drayton, B., \& Budinich, V. (2010). A new alliance for global change. Harvard Business Review, 12(5), 56-64.

Magretta, J. (2002). Why business models matter. Harvard Business Review, 80(5), 86-92.

Markides, C. C. (2008). Game-changing strategies: How to create new market space in established industries by breaking the rules. San Francisco: John Wiley \& Sons.

Mycoskie, B. (2011). Start something that matters. New York: Spiegel \& Grau.

Normann, R., \& Rammirez, R. (1993). From value chain to value constellation: Designing interactive strategy. Harvard Business Review, 71(4), 65-77.

Osterwalder, A., \& Pigneur, Y. (2009). Business model generation. Amsterdam: Self Published.

Parolini, C. (1999). The value net: A tool for competitive strategy. Chichester: John Wiley \& Sons Ltd..

Płoszajski, P. (2011). Management theory. Presentation from Lecture at Warsaw School of Economics, Warsaw, Poland.

Porter, M. E., \& Kramer, M. R. (2011). Creating shared value. Harvard Business Review, 89(1/2), 62-77.

TOMS About TOMS. (2012). Retrieved from http://www.myspace.com/tomsshoes

TOMS Founder Blake Mycoskie: Start Something That Matters. (2012). Retrieved from http://www.youtube.com/watch?v=0yJFv3gnJrU

TOMS How We Give. (2012). Retrieved from http://www.toms.com/how-we-give

TOMS One Day Without Shoes. (2012). Retrieved from http://www.toms.com/onedaywithoutshoes

TOMS One for One Giving Report. (2012). Retrieved from http://www.toms.com/media/files/8.24.11_GivingReport_Update.pdf

TOMS One for One. (2012). Retrieved from http://www.toms.com/our-movement/movement-one-for-one

TOMS Our Movement. $\quad$ (2012). Retrieved from http://www.toms.com/our-movement?icid=us-home-092011_134\&icid=us-home-092011_175

TOMS Why Shoes. (2012). Retrieved from http://www.toms.com/our-movement-why

Zott, C., Amit, R., \& Massa, L. (2010). The business model: Theoretical roots, recent developments, and future research. Working Paper WP-862, IESE Business School, University of Navarra, Navarra. 